\title{
Types of development paths and the hierarchy of the regional centres of Central and Eastern Europe
}

Ádám Páthy After the rapid transformation period of the Széchenyi István University 1990s, determined predominantly by the crisis E-mail: pathya@sze.hu effects of a radical political-economic transition, the reshaping of the spatial structure and urban networks slowed in the post-socialist countries of Central and Eastern Europe. The spillover effects of the market economy transition are fading, and cannot be generalized. Instead, other factors, such as involvement in global processes and the creation and exploitation of new types of synergies, become the main drivers of the differentiation and development in the urban system.

Keywords: This study attempts to explore the framework Central and Eastern Europe, and specifics of this new environment by examregional centres, ining resources for development in the Eastern spatial structure and Central European regional centres.

\section{Introduction}

Examining the different paths of the development of Central and Eastern European regional centres and analysing their positions in the spatial structure of the region are timely in many respects. On the one hand, the two and a half decades that have elapsed since the regime changes have provided sufficient time for the major regional centres to adapt and find their place within the conditions imposed by the new socio-economic environment. After the rapid transitional stage of the early 1990s, burdened by an economic crisis and the subsequent 'recovery' stage, the main factors defining the hierarchical ordering of cities and their development potential have changed (Cheshire-Hamilton 2000). Parallel to the de-emphasizing of the primary factors of production and, to some extent, geographical location, novel factors have begun to play a greater role in the differentiation and polarization of the urban network (Horváth 2014). The intensity and concentration of knowledge and information are catching up in importance to the concentration of production and the labour force and, thus, so is network cooperation.

On the other hand, the past two and a half decades have been sufficient time for a multi-stage development process to evolve. The first stage was 'crisismanagement', including coping with the crises resulting from rapid and radical eco-

Regional Statistics, Vol. 7. No. 2. 2017: 124-147; DOI: 10.15196/RS070202 
nomic and social transformation. This was followed by the 'learning of operation' stage which involved adjusting to the changed circumstances. Differences in terms of available resources resulted in variations in the speed and extent of transition. A significant proportion of cities did not get beyond the first or second stage. As a result, few reached the third phase which is based on forming and exploiting external conditions for their own interests and the effective mobilization of internal resources. Cities and urban regions that reached certain stages of transition more quickly and successfully gained major benefits in terms of the competition between cities, further increasing the gaps inherited from their starting position. This was a crucial factor in the new environment, where the mechanisms of central planning and regional equalization degraded and became unremarkable. For cities and regions that struggled (and continue to struggle) with restructuring, the concern is not only their lack of, or low level of competitiveness, but also the negative social and demographic processes that have 'exhausted' their human capital (Gorzelak 1998, Lintz et al. 2005). In general, we cannot say that the transition is complete. However, the urban network of the region has reached a new state determined mainly by novel factors of development. The primary objective of this study is to present an outline of this new state, exploring both the main developmental types of Central and Eastern European regional centres and the basic factors of the urban hierarchy and functional differentiation.

\section{Theoretical background and previous research}

During the past two decades, several studies have been conducted on the socioeconomic development of regional centres in our region after the transition, focusing on different aspects. The majority of them are confined to analysing single countries, although several papers examine a general framework or compare the development across countries.

The theoretical approach of post-socialist urbanization and urban development covers various elements and aspects of transformation. These include comparisons of the basic and specific features of socialist and post-socialist urbanization (Szelényi 1996), the modification of the economic framework of urban development (Kovács 1999, Stanilov 2007a, Turnock 1997), the restructuring of local government systems and the effects of policy interventions on urbanization (Bennet 1998, Stanilov 2007b), as well as the transformation of urban spatial structures and land use (Sykora 2008, Tsenkova-Nedovic-Budic 2006) among several other research fields.

While a theoretical approach enables us to evaluate the factors behind the transformation and development, it is more important to briefly review those studies that focus on the hierarchical and functional structure of the Central and Eastern European urban network.

Regional Statistics, Vol. 7. No. 2. 2017: 124-147; DOI: 10.15196/RS07202 
Models of the spatial structure of Europe and our region reflect the positions and development opportunities of prominent cities and metropolitan areas in the region (Lang 2015). Early European spatial structure models focused primarily on nodes and development zones and used a centre-periphery approach (e.g. the Blue Banana or Pentagon models). As a result, Central and Eastern Europe fell outside the core areas and, thus, did not receive much attention. However, since the second half of the 1990s, models that include potential development zones have been given increasing weight. These models, based on either zones or developmental axes, cover our region by extending the zones of the core regions towards Austria and the Czech Republic, or by extending the axes in the Berlin-Warsaw and ViennaBudapest-Belgrade directions (Szabó 2009).

In addition, in the 1990s, a new type of model emerged, slightly exceeding the mainstream centre-periphery relations and highlighting metropolitan regions as nodes and basic organizational units of the spatial structure. These growth centres are participants in the continental regional and urban competition (KunzmannWegener 1992). Therefore, this 'bunch of grapes' model places considerable emphasis on the development of cities and urban areas, and on the formation of a polycentric network.

The most influential model on the internal characteristics of the spatial structure of Central and Eastern Europe was proposed by Gorzelak (1996). This model assumes that regions with an affordable infrastructure and a favourable geographic location for business interactions, and centres with an adequate size and role have passed through a successful transition and formed a dynamic development zone in the region. This so-called Central and Eastern European boomerang spreads to the south-west from Gdansk, with Poznan and Wroclaw as its important nodes, through the Czech Republic, and then to the south-east, including Vienna, Bratislava, and Budapest (Gorzelak 1996). Thus, the zone is considered to be the Blue Banana of Central and Eastern Europe, with a weaker economic concentration and links between the nodes.

Other experiments have attempted to identify similar development zones in the region. These include the Central European Pentagon linking various capitals, or the 'dual banana' and 'second banana' concepts which define development zones that originate in German areas.

After the turn of the millennium, the main transitional trends in the region were concentration and polarization. The primary scenes of these processes are metropolitan areas that stand out in increasingly characteristic ways. These areas show the most significant degree of concentration of resources, and have become crucial to being competitive in terms of, for example, human capital, research and development, and the ability to absorb and adopt innovation. These are the primary factors that place a capital in a distinguished position (Rechnitzer 2016).

Regional Statistics, Vol. 7. No. 2. 2017: 124-147; DOI: 10.15196/RS07202 
The advanced processes of concentration and polarization, and the fact that the links between metropolitan areas are less strong than those in Western Europe, indicate that the presence of continuous developmental zones is less pronounced in the region. Instead, a kind of nodal structure prevails with a hierarchical distribution of centres and relatively lax inner linkages. Szabó and Farkas (2014) distinguished four levels of such nodes, as well as a special category (see Table 1).

Table 1

Hierarchy of nodes in the spatial structure of Central and Eastern Europe

\begin{tabular}{|c|c|c|}
\hline \multicolumn{3}{|c|}{$\begin{array}{l}\text { 1. Economic and social nodes with capital functions and of international and European } \\
\text { significance }\end{array}$} \\
\hline \multicolumn{3}{|c|}{ Vienna } \\
\hline \multicolumn{3}{|c|}{ 2. Social and economic nodes with capital functions and of European significance } \\
\hline \multicolumn{3}{|c|}{ Budapest, Bucharest, Prague, Warsaw } \\
\hline \multicolumn{3}{|c|}{ 3. Social and economic nodes with capital functions } \\
\hline \multicolumn{3}{|c|}{ Ljubljana, Bratislava, Zagreb } \\
\hline \multicolumn{3}{|c|}{ 4. Regional metropolises } \\
\hline Social and economic nodes & Economic nodes & Social nodes \\
\hline $\begin{array}{l}\text { Brno, Kosice, Krakow, Lodz, } \\
\text { Ostrava, Poznan, Wroclaw }\end{array}$ & $\begin{array}{l}\text { Graz, Innsbruck, Linz, } \\
\text { Salzburg }\end{array}$ & $\begin{array}{c}\text { Bialystok, Brasov, Bydgoszcz, } \\
\text { Constanta, Craiova, Galati, Iasi, } \\
\text { Cluj-Napoca, Lublin, Szczecin, } \\
\text { Timisoara } \\
\end{array}$ \\
\hline \multicolumn{3}{|c|}{ Special category: Central and Eastern European megalopoles } \\
\hline $\begin{array}{l}\text { a) Bytom, Chorzow, Dąbrowa } \\
\text { ska, Siemianowice Śląskie, Sosnowie } \\
\text { b) Gdansk, Gdynia, Sopot. } \\
\text { Source: Szabó-Farkas (2014). }\end{array}$ & $\begin{array}{l}\text { sian conurbationa), Trójmi } \\
\text { hicza, Gliwice, Jaworzno, Ka } \\
\text { więtochłowice, Tychy, Zabrze }\end{array}$ & $\begin{array}{l}\text { o b) } \\
\text { vice, Mysłowice, Piekary Ślaskie, Ru }\end{array}$ \\
\hline
\end{tabular}

Few nodes exist around which major development fields have formed, and these tend to be country capitals. The network elements of the spatial structure are mainly West-East transit corridors and are not necessarily connected to the nodes. Special regions are important elements of the spatial structure, embracing declining industrial and emerging tourist regions (Szabó-Farkas 2014). The 'emptying' of peripheral regions is far more rapid than in their Western European counterparts, and the weakness of the integration of these regions into the spatial structure reinforces the imbalances (Rechnitzer 2016).

Multidimensional studies on the spatial structure of the region partly support the general findings (Kincses-Nagy-Tóth 2014). However, a deeper analysis gives a more nuanced and precise picture of the region, highlighting the imbalances. Egri and Tánczos (2015) separate various layers of factors that form the spatial structure, and examine the interactions among them, distinguishing three major types of regions:

Regional Statistics, Vol. 7. No. 2. 2017: 124-147; DOI: 10.15196/RS07202 
1. Urban areas generating and concentrating development: This group includes the capital cities in the upper echelon, which dominate the spatial structure, such as Vienna, Budapest, Prague, and Warsaw, as well as Bucharest, with a slight lag behind them as a lopsided centre. Bucharest has high economic concentration and dynamics, but also has weak infrastructure and innovation potential. The first line of Polish regional centres (i.e. the Silesian conurbation) and the Austrian cities also belong to this group.

2. Attraction zone regions: These are essentially the agglomerations of metropolitan areas and their wider regions with favourable geographical locations and developed centres in close proximity (Western Poland, Czech Republic, Slovenia, Northern Transdanubia).

3. Rural and peripheral regions: The majority of regions in this group are concentrated in the Eastern areas (Eastern Poland, Romania, and Bulgaria) and include the rural areas of Hungary (Egri-Tánczos 2015).

In addition to the typology of the regions, the analysis highlights the relationships that exist between the factors which form the spatial structure and determine the imbalances in the spatial structure.

\section{Data and methodology}

This study covers Central and Eastern Europe that consists of nine countries, of which eight have regional centres suitable for our analysis (Slovenia has no cities with a population over 100,000, except for the capital, Ljubljana). The V4 countries (Czech Republic, Hungary, Poland, and Slovakia) are the most obvious parts of the core area of the region. The region also includes the 'remnants' of the Habsburg territories and the Austro-Hungarian Empire, which played a crucial role in shaping the historical and cultural character of the region, especially in the modernization process. Thus, Croatia and Slovenia are included, as is the only non-post-socialist country, Austria. Based on its current position and orientation, Romania is also regarded as part of the region. The country whose involvement may be considered the most doubtful is Bulgaria. In most regards, the country can be classified more as part of South-eastern Europe since its historical orientation, development and modernization path are slightly different from those of the other eight countries. However, based on the processes of the $20^{\text {th }}$ century, particularly from the period of the post-socialist transition, and with its accession to the European Union, Bulgaria is becoming integrated into East Central Europe.

The different nature and various distributions of the urban networks in the Central and Eastern European countries make it difficult to clearly designate the regional centres. The average size of second-tier cities with regional roles differs from country to country, as does the density of these networks. Therefore, for our empirical analysis, we use a classification based on an objective threshold by size rather

Regional Statistics, Vol. 7. No. 2. 2017: 124-147; DOI: 10.15196/RS07202 
than on supposed roles. Thus, the cities included in the study are those with a population greater than $100,000,{ }^{1}$ excluding the capitals of countries, yielding a sample of 82 cities.

Data from various sources were used in the analysis, based primarily on the Urban Audit and Eurostat regional databases. However, the data collection process showed that the range of comparable data for the entire region is relatively small and that the databases have significant deficiencies in terms of time series and the availability of data. In order to supplement and expand the data sets, territorial data modules of national statistical offices are used for those indicators that are comparable by measurement and category. This data collection method proved useful, providing longer time series on the population, as well as data on vital events and on the sectoral distribution of employment.

Basically, four types of indicators are used. The majority are specific and related to a particular year (2014, in most cases), and are the same for each country when the data collection was 'independent'. Some indicators are compared with an average value (e.g. gross domestic product [GDP] as a percentage of the EU average) or are proportional to the population. When 'spot' data are less suitable, yearly averages for a certain interval are used (e.g. yearly average of migration balance for fiveyear intervals). In addition, some indicators are intended to illustrate the dynamics of economic processes (e.g. growth rate of GDP).

For a handful of indicators, municipal data were not available for all the countries or cities and, thus, they are used on a higher territorial level (NUTS 3). The only important indicators of this type are related to the GDP. In this case, the problem of modified territorial units arises, primarily because, in several countries within the European Union, large cities are functioning as NUTS 3 units themselves. However, in the examined countries, this practice is less widespread and, for the most part, the capitals fall into this category. The only exception is Poland, where six cities (i.e. Gdansk, Lodz, Krakow, Poznan, Szczecin, and Wroclaw) constitute NUTS 3 level units. In these cases, 'agglomeration' units, in which these cities are also seats, are added to the data, with population weighting.

The 'thematic' dimensions of the analysis are configured by data reduction using a principal component analysis. The base indicators used in the process are standardized. For each dimension (i.e. economy, knowledge economy, demography, culture, and environment), a sufficient level of compression and applicability of the relevant indicators was achieved (see Table 2). The regional centres can be ranked based on these dimensions. Besides, it is also possible to identify homogeneous groups. This procedure was carried out using a $K$-means cluster analysis, given the sample size and the nature of the indicators. A separate cluster analysis explores the types of demographic processes. In addition to the classification, an examination of

${ }^{1}$ Including the core city only, not the whole metropolitan area.

Regional Statistics, Vol. 7. No. 2. 2017: 124-147; DOI: 10.15196/RS07202 
the balance of developmental factors is carried out to determine the weight of each dimension in the complex developmental score.

Table 2

\section{Constitution of the principal components}

\begin{tabular}{l|c}
\hline \multicolumn{1}{c}{ Economy (explained variance: 62\%, KMO: 0.617) } & 0.855 \\
Companies per 1,000 inhabitants & 0.739 \\
Cars per 1,000 inhabitants & 0.645 \\
Activity rate & 0.623 \\
Proportion of employees in the service sector & 0.524 \\
GDP per capita in PPS
\end{tabular}

Knowledge economy (explained variance: 67\%, KMO: 0.647)

Percentage of R\&D employment

Patent applications, 2010-2014

Employment rate in knowledge-intensive services

Proportion of people with tertiary degree

Students in tertiary education per 1,000 inhabitants 0.624

Demography (explained variance: 50\%, KMO: 0.622)

Death rate under 65 years

Natural change per 1,000 inhabitants, 2011-2015 yearly average

Migration balance per 1,000 inhabitants, 2011-2015 yearly average

Infant mortality per 1,000 births

Dependency ratio

Culture and environment (explained variance: 52\%, KMO: 0.627)

Number of crimes per 1,000 inhabitants

Visitors to cultural institutions

Number of cinema seats per 1,000 inhabitants

Number of available beds in accommodation establishments per 1,000 inhabitants

Average number of nights spent by tourists in accommodation establishments

Note: KMO: Kaiser-Meyer-Olkin test; PPS: purchasing power standard; R\&D: research and development. Unless otherwise specified, the indicators refer to 2014.

Source: Own calculation.

\section{The dimensions}

\section{Economy}

The indicators for the economy principal component can be divided into three groups. The first is related to production and income, the second measures the den-

Regional Statistics, Vol. 7. No. 2. 2017: 124-147; DOI: 10.15196/RS07202 
sity of enterprises and business demography, and the third group is associated with employment and unemployment. Of the fourteen starting variables, five remained to shape the final indicator, with 62 per cent explained variance.

Based on the principal component scores, we find a significant advantage in Austrian cities, followed, with some lag, by the large regional centres in Poland (Poznan, Wroclaw, Katowice, Krakow, and Gdansk). With the exception of Ostrava, the Czech cities also produce above-average values. In addition to the cities of these three countries, only two regional centres in Hungary (Győr, Székesfehérvár) and one in Croatia (Rijeka) show above-average performance. The other end of the scale comprises mostly Romanian and Bulgarian cities. Of these cities, only the two larger Romanian centres have a favourable geographical position (Cluj-Napoca, Timisoara), and the dynamically developing Varna stands out from those lagging behind. The Hungarian regional centres belong to the 'lower middle class' in terms of economic development, forming a relatively homogenous group. In this case, only Győr stands out to some extent.

Figure 1

\section{Relationship between the economic principal component score and} the GDP growth rate, 2010-2014

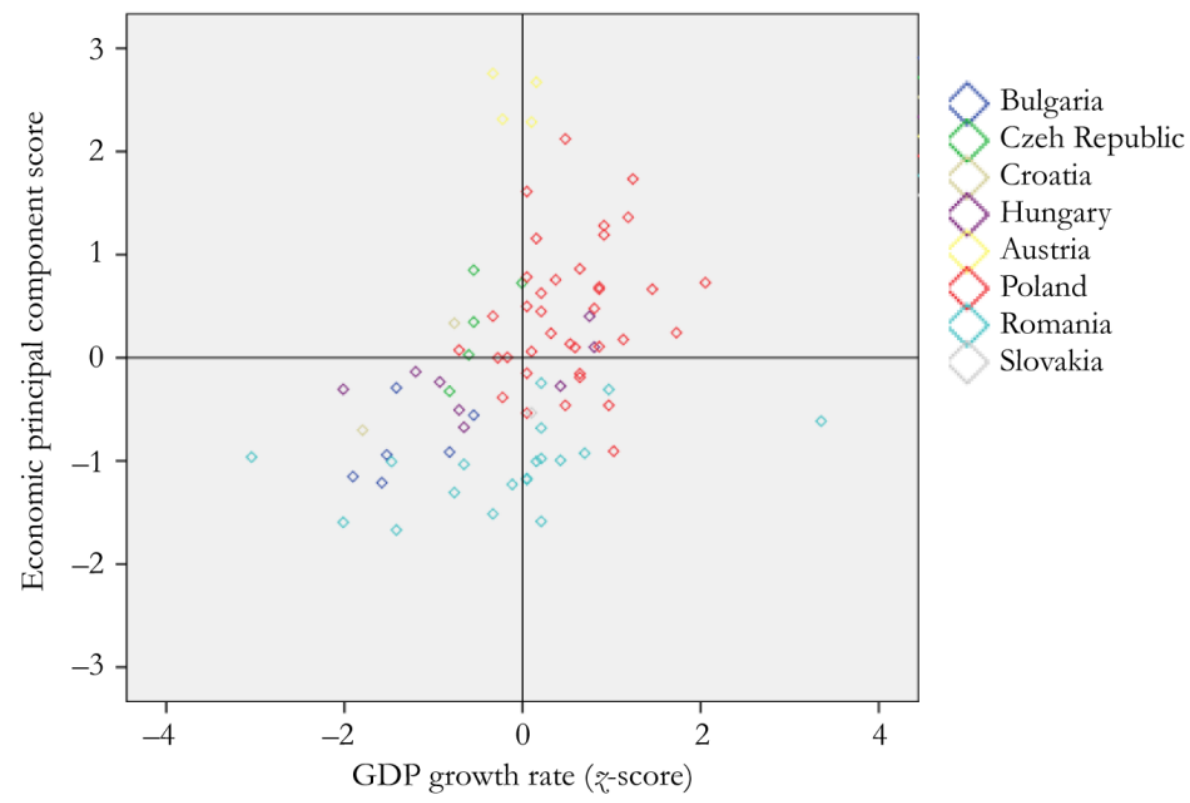

Source: Own calculation.

Regarding the spatial distribution of economic development, the West-East slope is prominent (see Appendix 1). In addition, economic status is correlated with

Regional Statistics, Vol. 7. No. 2. 2017: 124-147; DOI: 10.15196/RS07202 
the size of a city, but this rate varies by country. Especially strong links are found in the case of Polish cities, while in Hungary, the links are not considered significant. To investigate whether convergent trends are evident in terms of economic development, the economic factor scores are compared with the growth rate of GDP for the 2010-2014 period (see Figure 1). The two variables are significantly correlated with moderate strength, which suggests that polarization is increasing within the network of regional centres.

If we compare the economic development with the sectoral structure of production and employment, it is clear that industry does not have a positive impact. A significant negative correlation is observed between the economic principal component score and the industrial employment rate and between the economic principal component score and the share of the industry gross value-added produced. The quintiles composed of the economic principal component scores show that the share of employment per industry increases from top to bottom. The proportion in the top quintile is only 26 per cent and in the lowest quintile is 41 per cent. Only six cities are found in the top two quintiles with an above-average share of industrial employment, one of which is Györ.

\section{Knowledge economy}

The variables of the knowledge economy principal component can also be divided into three 'thematic' groups. These include indicators on qualifications and the institutional basis of higher education, data on research and development, and on the concentration of knowledge-intensive elements within the service sector. The principal component is based on five variables that explain 67 per cent of the variance.

The distribution of the principal component scores shows that for knowledge economy the degree of concentration in the case of the top-performing cities is the highest of the four dimensions examined. A relatively small group of cities are significantly better than those in the rest of the network. As in the case of the previous dimension, Austrian cities stand out. However, while they have similar performance in terms of economic development, there is a visible break in terms of the knowledge economy. Graz and Linz perform much better than Innsbruck and Salzburg do. The following group is similar to that of the economic status indicator, consisting of the biggest Polish regional centres. However, the same break is observable here, with Krakow, Poznan and Wroclaw belonging to a separate category. As regards knowledge economy, Czech cities are in a relatively better position than in the case of economic development. Brno has similar indicators to those of the Polish cities mentioned above. Here, the scores again reflect the West-East slope, but the composition of the cities that lag behind is not as homogenous as for the previous factor. The end of the list comprises largely the Romanian and Bulgarian cities, although the centres of rural regions in Poland and

Regional Statistics, Vol. 7. No. 2. 2017: 124-147; DOI: 10.15196/RS07202 
the cities of the Silesian conurbation, with the exception of Katowice, are also included in this group.

Overall, the geographical distribution and level of concentration of knowledge economy show a different picture to that of economic status. Geographical position is less important in this case. For example, smaller regional centres in Western Poland are found on the opposite ends of the scale with regard to the two factors. Their close proximity to the European core regions does not have perceptible positive effects on knowledge economy. In contrast, the centres of traditionally agrarian South-eastern Polish regions, with sparse urban networks (Lublin, Rzeszow), show a significant concentration of human capital (see Appendix 2). The correlations between the principal component scores and city population are similar in strength to those of the previous dimension.

Figure 2

Distribution of GDP per capita in purchasing power standard along the quintiles of knowledge economy principal component scores, 2014

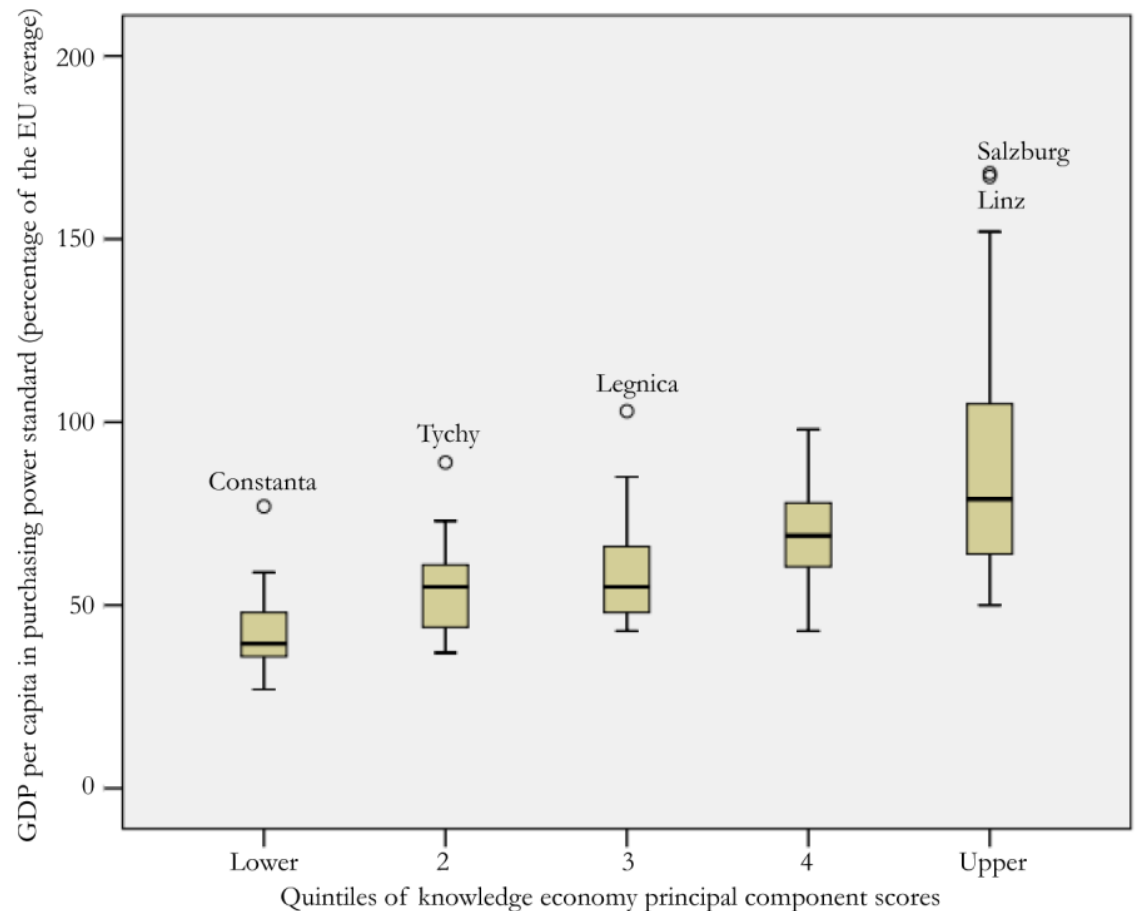

Note: The boxplots display the median (central line), the interquartile range (box), the full range (between the whiskers) and the outliers (points with city names).

Source: Own calculation.

Hungarian cities show a somewhat more differentiated picture than that of economic development. The relatively large university centres perform well, even on

Regional Statistics, Vol. 7. No. 2. 2017: 124-147; DOI: 10.15196/RS07202 
macro-regional level. For example, the scores show that Szeged is in the upper quintile, while Debrecen and Pécs appear in the second quintile. Previous studies related to the Hungarian urban network present a somewhat lopsided development of the regional centres. Cities with significant innovation potential have relatively weak economic performance. This finding cannot be generalized for the whole region, although this discrepancy is reflected in some countries. Figure 2 shows the distribution of GDP per capita in purchasing power standards along the quintiles of the knowledge economy principal component.

Overall, with regard to higher education, innovative activity, and advanced services, a more nuanced picture is evident, as in the case of the primary indicators of economic development. However, fundamental levels of inequalities and ruptures within the region are constituted in the same manner.

\section{Demography}

In parallel with the political changes in the socialist countries by the early 1990s, trends in urban-rural migration shifted noticeably. The majority of the Central and Eastern European regional centres experienced a population decrease in this decade, owing to the exodus from the cities to the rural areas on the one hand, and the accelerating natural decrease on the other. However, in several countries after the millennium, the demographic processes of regional centres began to differentiate. This is mainly due to the restarting of migration towards the cities entering a positive development path, thus providing better opportunities in the labour market and in terms of potential income, and to the metropolization processes of larger countries characterised by a multi-tiered network of regional centres.

In the case of larger cities that are considered primary targets for migrants, a transformation in the age structure is observable within the medium term, which has dynamizing effects on the natural demographic conditions. Of course, these processes cannot be reduced to the population flow towards the economically developed regions. In some peripheral areas of regions with higher fertility rates, the migration of a significant portion of the rural population surplus is towards the centres of their respective regions. In general, these cities do not show strong economic potential at the macro-regional level, but emerge from their close hinterlands. These processes are typical in the Eastern regions of Poland and Romania.

The principal component of demographic status consists of data on vital events, indicators of the age structure illustrating the 'inner' dynamics of the population, and migration statistics. The proportion of explained variance is smaller here than in the case of the other principal components (50 per cent), and, in general, the pairwise correlations among the initial variables are weaker.

As might be expected, in this case the distribution of cities is somewhat different, with the spatial polarization of the principal component scores showing a lower level (see Appendix 3). Economically developed Austrian and Polish cities have

Regional Statistics, Vol. 7. No. 2. 2017: 124-147; DOI: 10.15196/RS07202 
favourable demographic conditions, as do the regional centres of the Eastern part of Poland and Romania. The data confirm that the demographic crises of the traditional centres of heavy industry are permanent, the vital migration statistics and population structure indicators of the majority of these cities do not show any improvement, even two and a half decades after the transition. The thirteen cities in the most unfavourable situation (lagging by more than one standard deviation below the average) are former centres of heavy industry, except Pleven, which is the centre of a remote, rural Bulgarian region. Two Hungarian cities, Miskolc and Pécs, also fall into this category.

In order to make the two-sided nature of the demographic dynamics sensible, a $K$-means cluster analysis is performed on the basis of the indicators of the primary component (except for infant mortality). Six clusters are set up, and two groups of cities characterized by favourable demographic trends are separated. Dynamic eastern cities are more balanced than others by the sources of growth: their migration surplus is complemented by natural increase, but their mortality rates are high. The 'Western' model of demographic dynamics, mainly typical in Austrian and Czech cities, shows a slight natural decrease, a stable migration surplus, and exceptionally low mortality rates.

\section{Culture and environment}

This principal component is built from indicators of a different nature. It includes data on cultural institutions and cultural consumption, core indicators of tourism, and data related to the quality of the living environment. The principal component consists of six variables, two of which (number of visitors to cultural institutions and the infrastructure of recreational activities) are complex indicators. The explained variance is 52 per cent.

The principal component scores show the separation of the two Austrian cities with weaker performance in the knowledge economy (Innsbruck, Salzburg) and Krakow. The other two Austrian cities, along with Poznan, Wroclaw, Pécs, and Sibiu, constitute the second tier. The positions of Czech cities are relatively lower than those in the other three dimensions. The centres of the agricultural regions in Moldavia and Wallachia and the industrial towns of Silesia have the lowest scores. The West-East differences are significant, appearing a rupture rather than a slope (see Appendix 4).

\section{Ranking of cities}

Aggregating the four dimensions, a simple ranking of Central and Eastern European regional centres can be compiled. As expected, the Austrian cities top the list, followed by the major centres in Poland. Czech cities are close to the leading group,

Regional Statistics, Vol. 7. No. 2. 2017: 124-147; DOI: 10.15196/RS07202 
except the below-average Ostrava. Hungarian cities score near the average, making up a relatively homogenous group. Romanian and Bulgarian cities, primarily centres of remote rural regions with sparse urban networks, are at the bottom of the list. Table 3 shows the top and bottom ten cities, according to the aggregate score.

Table 3

The top and bottom ten cities by the complex development score, 2014

\begin{tabular}{l|rrr|r}
\multicolumn{2}{c}{ Top 10} & & \multicolumn{2}{c}{ Bottom 10} \\
\cline { 1 - 2 } \cline { 5 - 6 } \multicolumn{1}{c}{ City } & Score & & \multicolumn{1}{c}{ City } & Score \\
\cline { 1 - 2 } \cline { 5 - 6 } Innsbruck & 10.66 & & Bytom & -3.06 \\
Graz & 10.00 & & Wloclawek & -3.09 \\
Salzburg & 9.42 & & Ploiesti & -3.10 \\
Linz & 7.89 & & Burgas & -3.30 \\
Krakow & 7.46 & & Botosani & -3.38 \\
Wroclaw & 5.44 & & Ruse & -3.40 \\
Poznan & 4.94 & & Satu Mare & -3.67 \\
Gdansk & 3.78 & & Buzau & -4.04 \\
Rzeszow & 3.31 & & Pleven & -4.17 \\
Brno & 3.23 & & Braila & -5.90
\end{tabular}

Source: Own calculation.

With regard to the aggregation of the principal components, the balance of the various factors responsible for the development indicator is also examined. Breaking down the principal component scores to percentiles, each city has a value from 1 to 100 in each dimension. These scores indicate the complex development status on the one hand, and the weight of each dimension on the other. A comparison of the dimensions of the complex indicator shows two linear trends. In parallel with an increase in the level of overall development, the weight of the knowledge economy is also increasing, while that of demography is decreasing. In the next step, the average weights of the four components are examined by country (see Figure 3). The results show that Austrian cities are distinct from those in other countries, not only in the sense that their average developmental score is outstanding, but also because they are characterized by an almost perfect functional balance. In their case, the four factors have roughly the same level of involvement in the complex indicator. If we only separate the economic and non-economic dimensions, Poland also shows an equilibrium, although her deep structure is different: the traditional economic factors predominate over the knowledge economy, while the same level of relationship exists between demography and culture and environment.

Regional Statistics, Vol. 7. No. 2. 2017: 124-147; DOI: 10.15196/RS07202 
Figure 3

Average weight of dimensions in the complex development score, by country

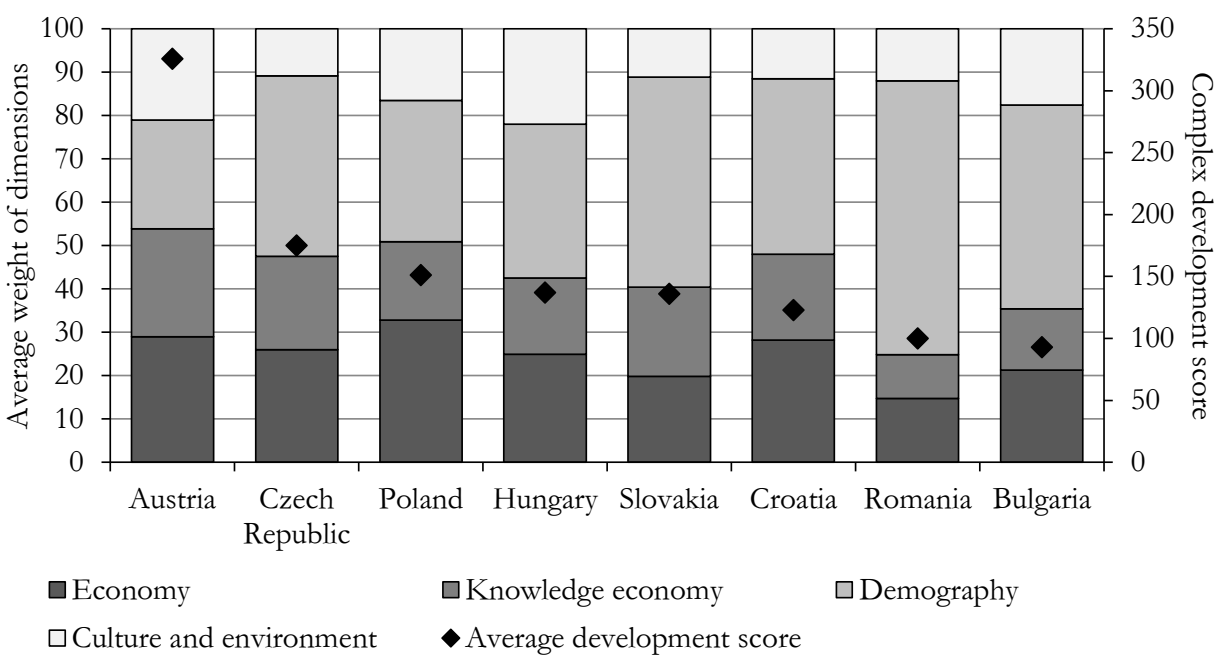

Source: Own calculation.

\section{Types and hierarchy of regional centres}

A $K$-means cluster analysis is conducted based on the four principal components in order to map the functional-hierarchical structure of the urban network of the region. The final cluster structure is divided into seven groups, two of which are specific, with a total of five cities. The remaining five clusters have a roughly similar number of membership, with an average of fifteen cities. The cluster structure does not reflect a hierarchical structure, although a fundamental arrangement is evident based on the developmental level. However, in some cases, specific factors are well manifested next to similar roles and levels of development.

Table 4

Final cluster centres based on the principal component scores

\begin{tabular}{l|c|c|c|r|r|r|c}
\hline & 1. & 2. & 3. & 4. & 5. & 6. & 7. \\
\hline Economy & 2.53 & 2.10 & 0.90 & -0.14 & -0.56 & 0.13 & -1.03 \\
Knowledge economy & 3.76 & 2.21 & 0.67 & -0.28 & -0.39 & -0.06 & -0.88 \\
Demography & 1.54 & 1.00 & 0.46 & 0.22 & 0.72 & -1.37 & -0.59 \\
Culture and environment & 1.10 & 3.85 & 0.36 & 0.56 & -0.51 & -0.29 & -0.71
\end{tabular}

Source: Own calculation.

Regional Statistics, Vol. 7. No. 2. 2017: 124-147; DOI: 10.15196/RS07202 


\section{Outstanding cities with a dominant knowledge economy / 2 cities/}

Only two cities, Graz and Linz, belong to this specific cluster. Their position is not determined primarily by their favourable economic situation, but by their outstanding performance in the knowledge economy. In the case of Austrian cities, which generally show high performance in the latter aspect, there is a kind of fracture. The leading positions of the two cities are illustrated not only in the present study, but also in earlier analyses on the knowledge economy and the role of universities in research and development (Fischer-Varga 2002), as well as in territorial aspects of the creative and cultural industry (Trippl et al. 2013). The advantage of these two cities is manifested strongly in the outstanding number of patent applications and their employment ratio in research and development and knowledge-intensive services. In the case of Linz, the pattern of transformation is clearly visible and exemplary, even on a European level. The city was one of the primary centres of traditional heavy industry in Austria during the 20th century, based primarily on the steel industry. From the 1980s onwards, economic diversification processes started at a fast pace, which, in addition to strengthening the role of small and medium-sized enterprises, was characterized by the active participation of large companies in the city and the region in investments in economic activities with high added-value. Today, cooperation between the primary actors (economic organizations, higher education, and local government) can be considered exemplary, providing a potential model for other major cities of the region. Similar processes can be observed in the case of Graz, with minor distinctions. The starting positions of these cities were more favourable, with Graz having a traditionally stronger regional role and a more diverse economic structure.

\section{Outstanding cities with high cultural capital / 3 cities/}

This specific cluster has the two 'remnant' Austrian cities, Innsbruck and Salzburg, as well as Krakow, which is the most populous regional centre in Poland and the overall study region. Cities in this cluster perform slightly worse in economic terms than those in the previous cluster. The specialty of their position is clearly defined by the outstanding concentration of cultural capital.

These positions are formed along slightly different emphases for the three cities. In terms of cultural institutions and events, Salzburg is outstanding. This has a significant positive effect on tourism, which is the primary factor behind the membership of Innsbruck in this cluster. Krakow is much more balanced and performs consistently above average with regard to the indicators of cultural capital and environment. The differences between the two Austrian cities and Krakow manifest themselves in economic terms. However, the indicators related to the knowledge economy and capital, especially those connected to higher education, show similar values. The fact that Krakow stands in this position and belongs to this cluster is

Regional Statistics, Vol. 7. No. 2. 2017: 124-147; DOI: 10.15196/RS07202 
due to the effect of its size. Beyond that, the city is considered to be the primary centre of culture in Poland, and its regional role is traditionally significant. This is not only true of its economic concentration, but also its human capital. Krakow is the largest academic centre among all the cities in this analysis.

\section{Fully fledged, balanced regional centres / 17 cities/}

The seventeen cities belonging to this cluster are considered fully fledged, balanced centres of the urban network on a macro-regional level. In terms of the examined dimensions, they perform above average in all respects, although we can identify different emphases and focal points with respect to the resources that determine their positions.

The first group of cities in this cluster gains the status of fully fledged regional centres by virtue of size, regional scope, and economic concentration. These include, on the one hand, the Polish cities with strong signs of metropolization, beyond their significant population (Gdansk, Poznan, Szczecin, Wroclaw), and Brno which is the primary centre of the Czech Republic, after the capital. These cities are separated from the cluster, to some extent, by their economic concentration. Here, the two dynamic centres of Western Poland, Poznan and Wroclaw, have the highest level.

The two cities with a population of more than half a million and an agglomeration over one million are considered to have the highest level of development potential in Poland, owing to the combined effect of their geographical location and the concentration of their population. The starting positions of the two cities necessary for the economic restructuring in the transition era were more favourable than those of their 'peers', namely these cities were (are) similar in size and had a more dominant traditional heavy industry or processing industry. In terms of economic indicators, in addition to their favourable position, dynamics is a factor that distinguishes Poznan and Wroclaw. Their positive tendencies are stronger and more significant than in the majority of cities in this cluster.

The second group consists of those cities in the Czech Republic and Western Poland that are on a lower tier in terms of their size and regional role than are the cities in the first group. Their position is strongly determined by their geographic location. These are regional centres with relatively significant educational and cultural functions (Bydgoszcz, Pilsen, Torun), as well as cities with a local economy based on innovative industrial sectors (Opole, Zielona Góra).

As slight geographical 'outliers', the two major centres in South-eastern Poland, Lublin and Rzeszow, also belong to this cluster. Their membership is based partly on mechanisms of Polish regional policy, which builds strongly on the capacity and quality development of higher education, and encourages knowledge-intensive activities as a tool through which the Eastern regions can catch up. The presence of these two cities in this cluster is largely due to the outstanding values of indicators related to higher education and the qualifications of the workforce.

Regional Statistics, Vol. 7. No. 2. 2017: 124-147; DOI: 10.15196/RS07202 
Katowice also has a special position in this cluster. The city is the centre of the Silesian conurbation which developed mainly on the basis of traditional heavy industry. Most of the cities located in this area that are characterized as industrial towns lag behind, but the dominant role of Katowice in service and institutional activities in the region is clearly evident. The negative demographic trends, considered to be general in the region, slightly separate Katowice from the other cities of the cluster.

\section{Secondary centres / 10 cities/}

The ten cities of this cluster are generally characterized by weaker economic performance than that of the fully fledged regional centres, as well as a lower level of regional scope and attraction, although with sufficient development potential. Their vast majority are Hungarian and Polish cities.

The Polish cities represent two basic types. First, there are two cities located in the 'shadow' of the major centres, but in the case of Gorzow Wielkopolski, the geographic location, and in the case of Kielce, the relatively important regional role ensure their favourable positions. The other two cities are located in Upper Silesia and have good economic and employment potentials, mainly owing to the vehicle industry. Fiat operates a factory in both Bielsko-Biala and Tychy.

Five of the eight Hungarian regional centres belong to this cluster. Therefore, those differences that were pronounced in the domestic analysis have reduced significantly at the macro-regional level. One possible reason is that Hungarian regional centres and their hinterlands have similar and quite low population weights and economic concentrations in the macro-regional comparisons. Thus, cities with a relatively strong economy, such as Györ or Kecskemét, are unable to achieve the same level as the second-tier regional centres of the Czech Republic or Western Poland. However, the asymmetry observable in the domestic analysis is partly confirmed here. While Győr and Székesfehérvár have relatively good economic indicators, they lag behind in terms of their knowledge economy and human capital, just as the Polish cities in this cluster do. Szeged is considered atypical with an opposite relationship for these two factors. One Romanian city, Sibiu, belongs to this cluster. Its economic indicators are only slightly better than its environment, but its performance in terms of culture and environment is well above average.

\section{'Dynamic' Eastern cities / 19 cities/}

This is the largest cluster with nineteen members. The vast majority of these are located in the Eastern part of the region, with nine cities in Romania. However, they possess a relatively favourable position compared to their environment.

Romania is represented by two slightly different groups of cities within the cluster. The first includes the traditional major centres of Transylvania and the Partium

Regional Statistics, Vol. 7. No. 2. 2017: 124-147; DOI: 10.15196/RS07202 
(i.e. Cluj-Napoca, Oradea, and Timisoara), which possess an advantageous position in Romania with respect to foreign direct investment, and their economic development lags only slightly behind the average level of the region. The other type is represented by the larger cities outside the Carpathian Mountains, which are hindered in their development in comparison with the first group, but rise from their hinterlands like islands. Thus, they have the ability to attract immigrants from rural areas, ensuring a stable population increase. These trends are manifested most significantly in the case of Iasi, but the smaller Bacau has the same characteristics.

Bulgaria's two largest and, in the last decade, most dynamically developing cities, Plovdiv and Varna, also belong to this cluster. In the case of both cities, suburbanization and the expansion of agglomeration are highly evident processes. Other members of this cluster are Debrecen, Split, and the only Slovakian town in this study, Kosice. The four Polish cities and the one Czech city in the cluster represent peripheral geographic locations, except for Rybnik in Upper Silesia.

\section{Cities lagging behind (industrial) /15 cities/}

The first cluster of the two characterized by a lack of resources and significant lag includes former or actual centres of heavy industry. The two exceptions are Kalisz and Lodz. In the case of these cities, it is clear that the problems of industrial restructuring have a long-term hindering impact on their development. In this cluster, the demographic trends are highly unfavourable. Almost all of the cities show a stable, but negative balance of migration from the early 1990s or even from the previous decade. As a result, the age structure shows a significant rate of ageing.

Six of the cities are located in Silesia. However, in a wider scope, Czestochowa and Ostrava are also classified as part of this region. In terms of the traditional foundations of economic structure and the process of restructuring, the two cities on the Polish side of the Sudeten, Legnica and Walbrzych, built on coal- and ore mining, are in a similar situation. Two Hungarian cities, Miskolc and Pécs, complete this cluster, and have similar problems and processes.

Lodz is a special case in this cluster, differing from the other centres of heavy industry in its size, regional role, and economic endowments. Still, it faces the same industrial restructuring problems that this group does. The economy of the city was dominated by the textile industry before the transition. Then, after its decline, economic restructuring began in a more favourable environment. However, the process is slow and cannot be considered complete. Lodz drops behind the other two similar-sized Polish cities. Although its economic indicators stand out from this cluster and the tertiarization process is relatively fast, its unfavourable demographic trends are more pronounced than in the heavy industry centres. Since 1990, the city has lost nearly 20 per cent of its population and, while the rate of population decline has continued to slow in the majority of Upper Silesian cities in the past five years, in Lodz, it has remained stable.

Regional Statistics, Vol. 7. No. 2. 2017: 124-147; DOI: 10.15196/RS07202 


\section{Cities lagging behind (peripheral) / 16 cities/}

The disadvantageous position of this cluster is not a result of its industrial past, but rather of its peripheral position. A considerable proportion of these cities are centres of rural areas or are located in the 'shadow' of bigger cities. Most of the cities in this group are Romanian and Bulgarian towns with very weak economic performance and potential.

The cluster includes Romanian cities located outside the Carpathians, with two exceptions (Arad and Satu Mare), and mainly Wallachian cities. The situation of Constanta merits special mention, as the largest city of this cluster with a population of 300,000. Even with its seaport and relatively good transport links, the city has been unable to progress beyond the category of the regional centres that lag behind.

There is a significant contrast in the case of Bulgaria. Apart from the two relatively dynamic centres (Plovdiv and Varna), the other Bulgarian cities all belong to this cluster. These cities are characterized by a high level of emigration and population decline, which exceeds even that of industrial towns. Lastly, the cluster membership is complemented by three Polish cities, of which Elblag and Radom are centres of remote areas.

Figure 4

Distribution of cities by the clusters

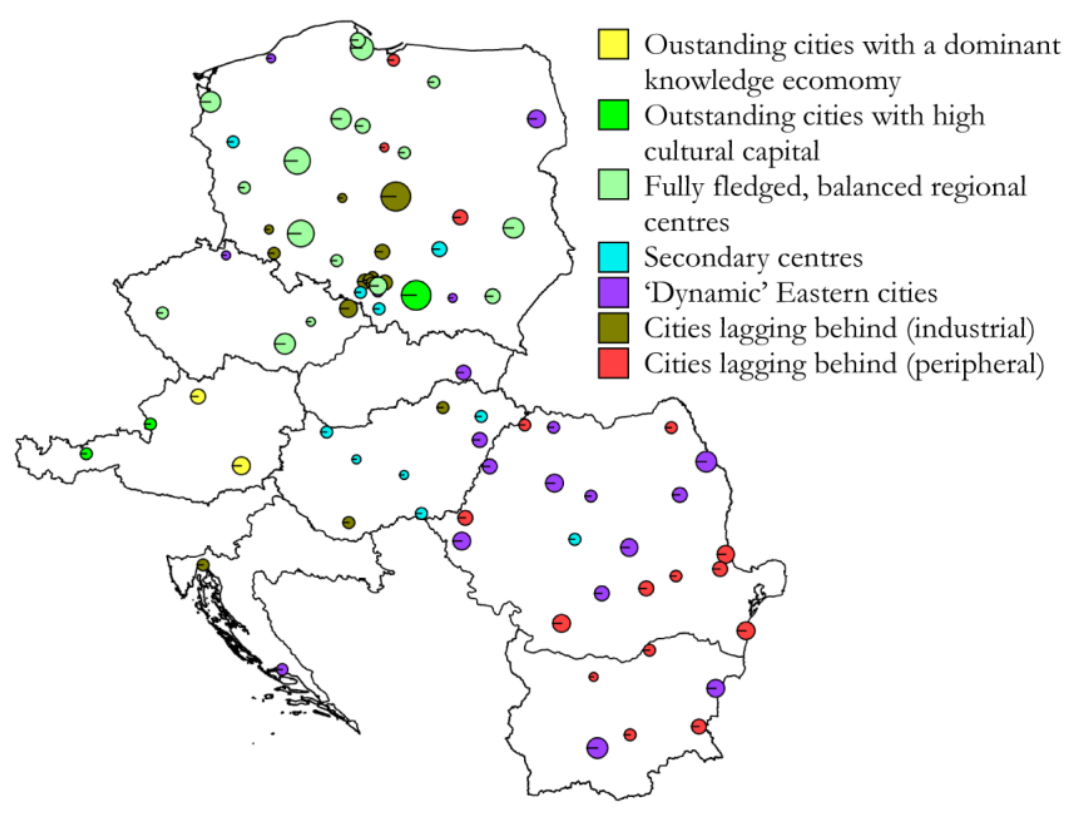

Source: Own elaboration.

Regional Statistics, Vol. 7. No. 2. 2017: 124-147; DOI: 10.15196/RS07202 


\section{Conclusions - primary factors determining the hierarchy of Central and Eastern European regional centres}

The cluster structure revealed in this study confirms many of the main findings of previous studies on the spatial structure and regional inequalities of the region. In terms of shaping the hierarchy of Central and Eastern European regional centres, the following factors play major roles:

1. Size and concentration. There is a clear and strong relationship between the size of cities and urban areas and their position in the network hierarchy. On the one hand, regional centres with an adequate population concentration, in general, occupy higher positions in their regions. For example, the big Polish regional centres are the largest elements of the network and hold prominent positions. On the other hand, the relationship is also evident in countries and regions with less favourable geographic locations and a lower level of economic development. The two largest regional centres in Bulgaria clearly represent the second level, behind the capital, while Lublin, the biggest city in Eastern Poland, also stands out among the smaller centres of the region.

2. Geographical location, West-East slope. With regard to specific dimensions, geographical position plays an important role in creating the complex cluster structure. The effects of the traditional inequalities in the region are evident in the density and development of the urban network, and in the spatial organizing functions of the cities. The rupture between the cities in Austria and those in other countries is clearly visible, as are the traditional inner disparities of the region. Romanian and Bulgarian cities that perform somewhat better than other cities in the two countries join the network of the macro-region at a low level.

3. 'National' effect. The noticeable differences between the regional centres in the domestic network are notably reduced at the macro-regional level, with the positions and types of cities in most countries showing relative homogeneity. The lone exception is Poland which has easily detectable levels formed by the sizes of the cities and the regional inequalities.

4. Structural effect. Here, the effects of several factors prevail. It is important to highlight the inherited economic structure which is a crucial determinant in the case of the industrial regions. The majority of cities that were key targets of socialist industrialization largely maintain their unfavourable positions two and a half decades after the beginning of the transition. The situation is quite similar in the centres of the rural areas, where the potential of the knowledge economy and innovation generally lack resources.

Regional Statistics, Vol. 7. No. 2. 2017: 124-147; DOI: 10.15196/RS07202 


\section{REFERENCES}

BennetT, R. J. (1998): Local Government in Postsocialist Cities. In: ENYEDI, Gy. (ed.): Social Change and Urban Restructuring in Central Europe pp. 35-54., Akadémiai Kiadó, Budapest.

Cheshire, P.-HAmilton, I. (2000): Urban Change in an Integrating Europe In: Petrakos, G.-MAiER, G.-GorZELAK, G. (eds.): Integration and Transition in Europe: the Economic Geography of Interaction pp. 100-130., Routledge, London-New York.

EGRI, Z.-TÁNCZOS, T. (2015): Spatial Layers and Spatial Structure in Central and Eastern Europe Regional Statistics 2 (1): 34-61. http://dx.doi.org/10.15196/RS05203

FIsCHer, M.-VARGA, A. (2002): Geographic Spillovers of University Research: on Patent Activities of the High Technology Sectors in Austria In: Ács, Z.-Groot, H.NiJKAmp, H. (eds.): The Emergence of the Knowledge Economy. pp. 139-154., Springer, Berlin.

Gorzelak, G. (1996): The Regional Dimension of Transformation in Central Europe Routledge, London-New York.

GorzelaK, G. (1998): Regional Development and Planning in East Central Europe In: KeAn, M (ed.): Regional Development and Employment Policy. Lessons from Central and Eastern Europe pp. 62-76., ILO, Geneva.

Horváth, Gy. (2014): Spaces and Places in Central and Eastern Europe - Historical Trends and Perspectives Routledge, London - New York.

KINCSES, Á.-NAGY, Z.-TÓTH, G. (2014): Modelling the spatial structure of Europe Regional Statistics 4 (2): 40-54. http://dx.doi.org/10.15196/RS04203

KovÁCS, Z. (1999): Cities from state-socialism to global capitalism: an introduction Geojournal 49 (1): 1-6. http://dx.doi.org/10.1023/A:1007048819606

Kunzmann, K.-Wegener, M. (1992): The Pattern of Urbanization in Western Europe Ekistics. 58: 282-291.

LANG, T. (2015): Socio-economic and political responses to regional polarisation and sociospatial peripheralisation in Central and Eastern Europe: a research agenda Hungarian Geographical Bulletin 64 (3): 171-185. http://dx.doi.org/10.15201/ hungeobull.64.3.2

LINTZ, G.-MÜLLER, B.-FINKA, M. (2005): Introduction: The Challenge of Structural Change for Industrial Cities and Regions in the CEE Countries In: MÜLLER, B.FINKA, M.-LinTZ, G. (eds.): Rise and Decline of Industry in Central and Eastern Europe pp. 1-24., Springer, Berlin - Heidelberg - New York.

RECHNitZER, J. (2016): Elmozdulások és törésvonalak Kelet-Közép-Európa térszerkezetében Tér és Társadalom 30 (4): 36-53. http://dx.doi.org/10.17649/ TET.30.4.2811

STANILOV, K. (2007a): Taking stock of post-socialist urban development: A recapitulation. In: StAnilov, K. (ed.): The Post-Socialist City - Urban Form and Space Transformations in Central and Eastern Europe after Socialism pp. 3-20., Springer, Dordrecht.

STANILOV, K. (2007b): Urban development policies in Central and Eastern Europe during the transition period and their impact of urban form In: STANILOV, K. (ed.): The

Regional Statistics, Vol. 7. No. 2. 2017: 124-147; DOI: 10.15196/RS07202 
Post-Socialist City - Urban Form and Space Transformations in Central and Eastern Europe after Socialism pp. 347-360., Springer, Dordrecht,

SYKORA, L. (2008): Revolutionary change, evolutionary adaptation and new path dependencies: socialism, capitalism and transformations in urban spatial organizations In: Strubelt, W.-GorzelaK, G. (eds.): City and Region pp. 283-295., Budrich UniPress, Leverkusen.

SzABÓ, P. (2009): Európa térszerkezete különböző szemléletek tükrében Földrajzi Közlemények. 133 (2): 121-134.

SzABÓ, P.-FARKAS, M. (2014): Kelet-Közép-Európa térszerkezeti képe Tér és Társadalom 28 (2): 67-86. http://dx.doi.org/10.17649/TET.28.2.2612

SZELÉNYI, I. (1996): Cities Under Socialism-and After In: ANDrusZ, G.-HARLOE, M.SZELÉnyi I. (eds.): Cities After Socialism - Urban and Regional Change and Conflict in Post-Socialist Societies pp. 286-317., Blackwell, Oxford.

TRIPPL, M.-TÖDTLING, F.-SCHULDNER, R. (2013): Creative and cultural industries in Austria In: LAZZARETTI, L. (ed.): Creative Industries and Innovation in Europe. Concepts, measures and comparative studies pp. 86-102., Routledge, London New York.

Tsenkova, S-Nedovic-Budic, Z. (eds.) (2006): The Urban Mosaic of Post-Socialist Europe - Space, Institutions and Policy Physica-Verlag, Heidelberg.

TURNOCK, D. (1997): Urban and regional restructuring in Eastern Europe Geojournal. 42 (4): 437-464. http://dx.doi.org/10.1023/A:1006800930821

Regional Statistics, Vol. 7. No. 2. 2017: 124-147; DOI: 10.15196/RS07202 


\section{Appendix}

1. Distribution of regional centres by the quintiles of the economy principal component scores

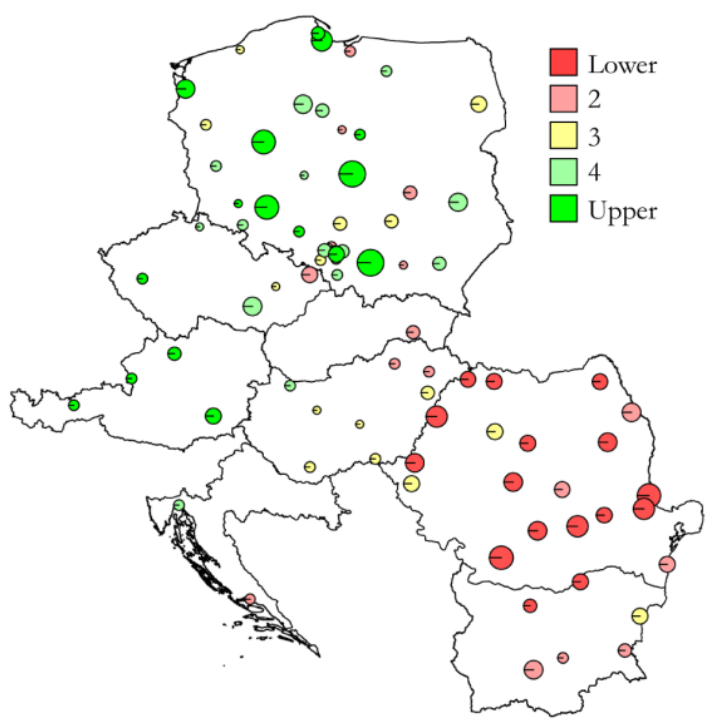

Source: Own elaboration.

2. Distribution of regional centres by the quintiles of the knowledge economy principal component scores

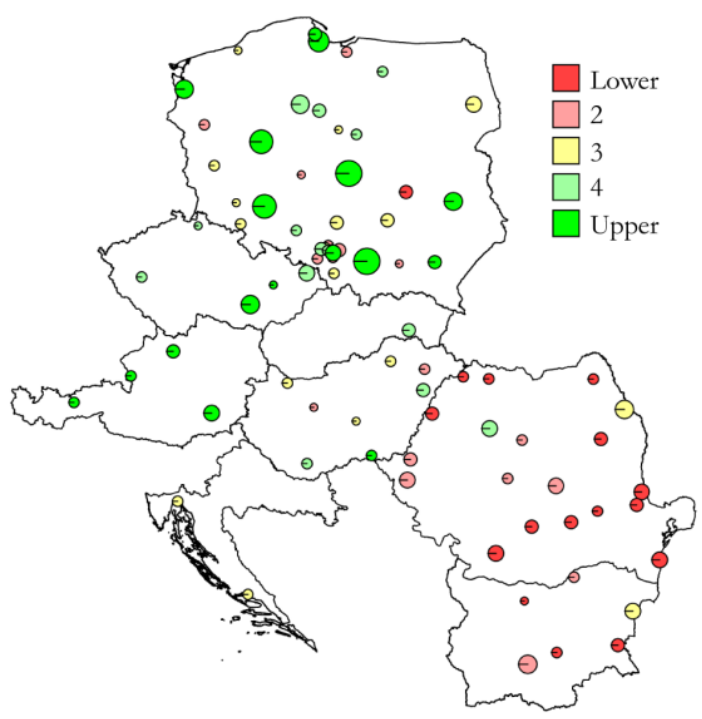

Source: Own elaboration.

Regional Statistics, Vol. 7. No. 2. 2017: 124-147; DOI: 10.15196/RS07202 
Types of development paths and the hierarchy of the regional centres of Central and Eastern Europe

3. Distribution of regional centres by the quintiles of the demography principal component scores

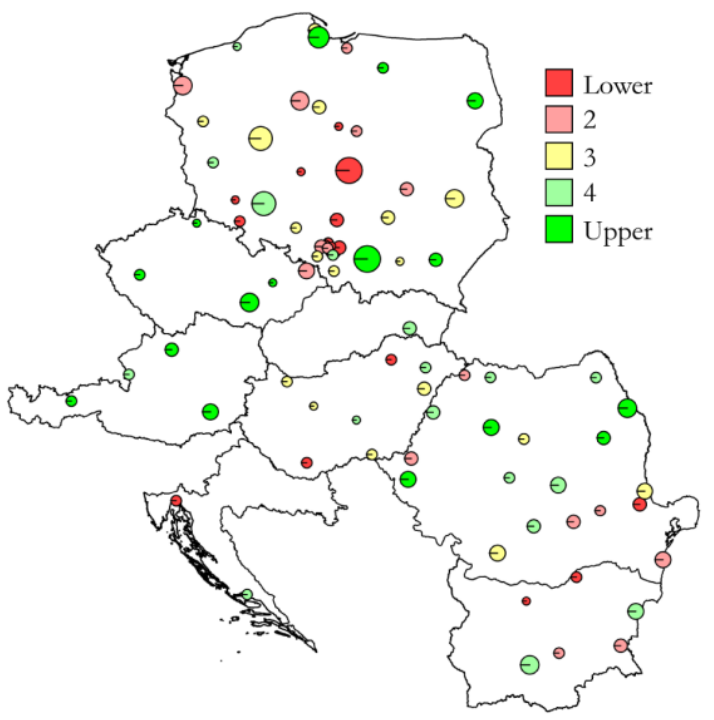

Source: Own elaboration.

4. Distribution of regional centres by the quintiles of culture and environment principal component scores

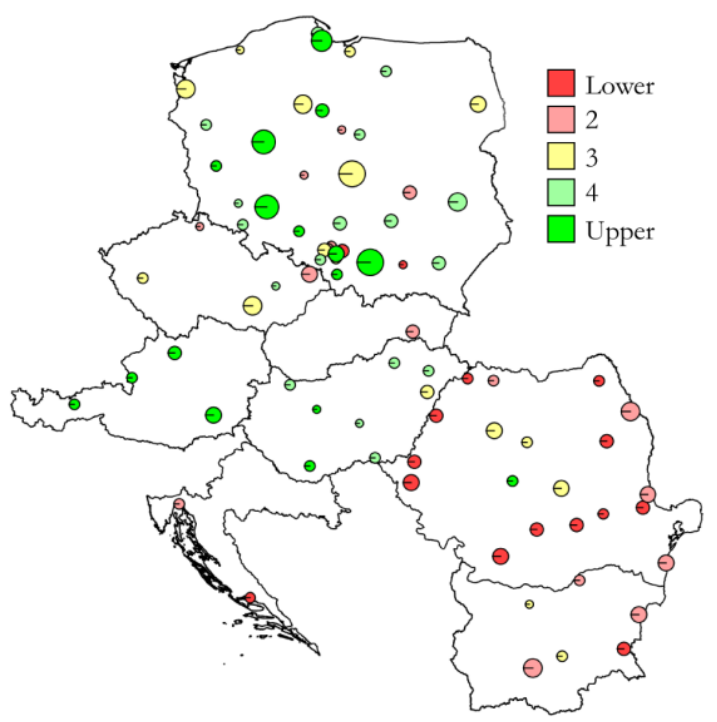

Source: Own elaboration.

Regional Statistics, Vol. 7. No. 2. 2017: 124-147; DOI: 10.15196/RS07202 